\title{
Correlates of anaemia in pregnant urban South Indian women: a possible role of dietary intake of nutrients that inhibit iron absorption
}

\author{
Tinu Mary Samuel ${ }^{1,2}$, Tinku Thomas ${ }^{1}$, Julia Finkelstein ${ }^{3,4}$, Ronald Bosch ${ }^{5}$, \\ Ramya Rajendran ', Suvi M Virtanen ${ }^{2,6}$, Krishnamachari Srinivasan ${ }^{3}$, Anura V Kurpad' \\ and Christopher Duggan $3,7, *$ \\ 'Division of Nutrition, St John's Research Institute, Bangalore, India: ${ }^{2}$ Division of Epidemiology, School of Health \\ Sciences, University of Tampere, Tampere, Finland: ${ }^{3}$ Department of Nutrition, Harvard School of Public Health, \\ Boston, MA, USA: ${ }^{4}$ Division of Nutritional Sciences, College of Human Ecology, Cornell University, Ithaca, NY, \\ USA: ${ }^{5}$ Department of Biostatistics, Harvard School of Public Health, Boston, MA, USA: ${ }^{6}$ The Unit of Nutrition, \\ National Institute for Health and Welfare, Helsinki, Finland: ${ }^{7}$ Division of Gastroenterology and Nutrition, \\ Children's Hospital - Boston, 300 Longwood Avenue, Boston, MA 021 15, USA
}

Submitted 26 September 2011: Final revision received 8 March 2012: Accepted 15 March 2012: First published online 11 May 2012

\begin{abstract}
Objective: To identify correlates of anaemia during the first trimester of pregnancy among 366 urban South Indian pregnant women.

Design: Cross-sectional study evaluating demographic, socio-economic, anthropometric and dietary intake data on haematological outcomes.

Setting: A government maternity health-care centre catering predominantly to the needs of pregnant women from the lower socio-economic strata of urban Bangalore.

Subjects: Pregnant women ( $n$ 366) aged $\geq 18$ and $\leq 40$ years, who registered for antenatal screening at $\leq 14$ weeks of gestation.

Results: Mean age was 22.6 (SD 3.4) years, mean BMI was $20 \cdot 4$ (sD 3.3) kg/m $\mathrm{m}^{2}$ and $236(64.5 \%)$ of the pregnant women were primiparous. The prevalence of anaemia $(\mathrm{Hb}<11 \cdot 0 \mathrm{~g} / \mathrm{dl})$ was $30 \cdot 3 \%$ and of microcytic anaemia (anaemia with mean corpuscular volume $<80 \mathrm{fl}$ ) $20 \cdot 2 \%$. Mean dietary intakes of energy, $\mathrm{Ca}, \mathrm{Fe}$ and folate were well below the Indian RDA. In multivariable log-binomial regression analysis, anaemia was independently associated with high dietary intakes of Ca (relative risk; 95\% CI: $1 \cdot 79 ; 1 \cdot 16,2 \cdot 76)$ and $\mathrm{P}(1 \cdot 96 ; 1 \cdot 31,2 \cdot 96)$ and high intake of meat, fish and poultry $(1 \cdot 94 ; 1 \cdot 29,2 \cdot 91)$.

Conclusions: Low dietary intake of multiple micronutrients, but higher intakes of nutrients that inhibit Fe absorption such as $\mathrm{Ca}$ and $\mathrm{P}$, may help explain high rates of maternal anaemia in India.
\end{abstract}

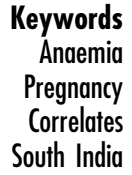

Keywords Pregnancy South India
Anaemia is a global public health problem that affects nearly 2 billion people in both developed and developing countries $^{(1)}$. Anaemia is highly prevalent among pregnant women in developing countries and is associated with poor pregnancy outcomes ${ }^{(2)}$. Anaemia in early pregnancy is associated with a $50 \%$ greater risk of inadequate weight gain for gestation ${ }^{(3)}$. The risk of preterm delivery is increased by $10-40 \%$ with mild anaemia ${ }^{(4)}$. The National Family Health Survey reported the prevalence of anaemia among pregnant women in India to be $59 \%{ }^{(5)}$. A survey among pregnant women from sixteen districts of eleven states in India showed that $61.0 \%$ to $96 \cdot 8 \%$ of pregnant women were anaemic $(\mathrm{Hb}<11 \mathrm{~g} / \mathrm{dl})^{(6)}$. Despite the ongoing national anaemia prophylaxis programme of $\mathrm{Fe}$ and folic acid supplementation to pregnant women, two large national surveys ${ }^{(5,7)}$ have indicated that there has been little change in the prevalence of anaemia and the adverse consequences associated with it.

Studies conducted in India suggested that micronutrient deficiencies ( $\mathrm{Fe}$, folate and vitamin $\mathrm{B}_{12}$ ) are the primary cause of anaemia in pregnancy ${ }^{(8)}$. Dietary intake surveys among pregnant women show low intake of several key micronutrients ${ }^{(9)}$ and subclinical deficiencies of riboflavin, pyridoxine and folic acid have been reported $^{(10)}$. The relative contribution of each of these factors to anaemia in pregnancy often varies by geographical location, season and dietary intake ${ }^{(11)}$. Even within India there are wide state-level variations in the 
prevalence of moderate and severe anaemia ${ }^{(7,12)}$, often attributed to differences in the simultaneous presence of several micronutrient deficiencies in addition to $\mathrm{Fe}$ deficiency, acute and chronic infections and differences in bioavailability of various micronutrients in the diet ${ }^{(13)}$. Despite a literacy rate of $68 \cdot 1 \%$ among women in Karnataka $^{(14)}$ and $85 \cdot 3 \%$ of the women having received antenatal care ${ }^{(15)}$, the prevalence of anaemia among pregnant women in Karnataka remains $47 \cdot 6 \%{ }^{(16)}$. We therefore were interested to determine the modifiable risk factors associated with anaemia among pregnant women in urban Karnataka early in their pregnancy.

\section{Materials and methods}

\section{Study design}

We performed a cross-sectional study among a cohort of pregnant women enrolled in a randomized controlled trial of vitamin $\mathrm{B}_{12}$ supplementation (NCT00641862). The study was conducted at Hosahalli Referral Hospital, Bangalore, Karnataka, South India. This government maternity healthcare centre caters predominantly to the needs of pregnant women from the lower socio-economic strata of urban Bangalore and has approximately 200 deliveries per month. Pregnant women were enrolled in early pregnancy ( $\leq 14$ weeks of gestation) from December 2008 to November 2010. The pregnant women are currently being followed through 2 years postpartum as part of the ongoing trial. The institutional review boards at St John's Medical College Hospital and Harvard School of Public Health approved all study procedures, and written informed consent was obtained from each participant at enrolment.

\section{Study population}

All pregnant women aged $\geq 18$ and $\leq 40$ years, who were $\leq 14$ weeks of gestation and registered for antenatal screening at the Hosahalli Referral Hospital, were invited to participate in the study. Pregnant women with multiple gestation, those with a clinical diagnosis of chronic illness (diabetes mellitus, hypertension, heart disease or thyroid disease), those who tested positive for HbSAg (surface antigen of the hepatitis B virus), HIV or syphilis, those who anticipated moving out of the city before delivery, those who were already consuming vitamin $\mathrm{B}_{12}$ supplements and those who had been treated for infertility were excluded.

Of the 1376 pregnant women who were contacted at the antenatal clinic during the study period, 958 were excluded for the following reasons: planning to deliver outside Bangalore at maternal home town ( $n 836)$; wishing to terminate the pregnancy ( $n$ 67); age $<18$ years $(n 4)$; history of hypertension $(n 7)$; previous Caesarean section ( $n$ 4); and pregnancy was not confirmed ( $n$ 40). Of the remaining 418 pregnant women who were considered eligible fifty-two declined to participate, leaving 366 who consented.

\section{Sociodemographic and antbropometric information}

The pregnant women were interviewed by trained research assistants to obtain sociodemographic information. Gestational age (in weeks) was calculated from the reported first day of the last menstrual period. A digital balance (Salter's 9016, Tonbridge, Kent, UK) was used to record the weights of all mothers to the nearest $100 \mathrm{~g}$. Measurements of height were made using a stadiometer to the nearest $0 \cdot 1 \mathrm{~cm}$. Mid-upper arm circumference was measured to the nearest $0 \cdot 1 \mathrm{~cm}$ using a plastic measuring tape and triceps skinfold was measured using a Holtain calliper (Crosswell, Crymych, UK). BMI was calculated as weight in kilograms divided by the square of height in metres $\left(\mathrm{kg} / \mathrm{m}^{2}\right)$.

\section{Haematological data}

Blood was drawn from pregnant women after an overnight fast by venepuncture and collected in both EDTA-containing and plain Vacutainer ${ }^{\mathrm{TM}}$ tubes (BD Diagnostics, Franklin Lakes, NJ, USA). Hb and complete blood count were measured on an automated Coulter counter (ABX Pentra $60 \mathrm{C}+$; Horriba Ltd, Kyoto, Japan). Anaemia was defined as $\mathrm{Hb}<11 \cdot 0 \mathrm{~g} / \mathrm{dl}$ and severe anaemia as $\mathrm{Hb}<7 \cdot 0 \mathrm{~g} / \mathrm{dl}^{(1)}$. Microcytosis was defined as mean corpuscular volume $(\mathrm{MCV})<80 \mathrm{fl}^{(17)}$, while microcytic anaemia was defined as anaemia with $\mathrm{MCV}<80 \mathrm{fl}$. Haematocrit was considered to be low in pregnancy at values $<33 \%{ }^{(18)}$ while the reference range for red-cell distribution width was considered to be $11 \cdot 5 \%$ to $14 \cdot 5 \%{ }^{(17)}$.

\section{Dietary data}

A pre-tested interviewer-administered FFQ was used to assess the habitual dietary intake for the three months preceding the date of the pregnant women's enrolment into the study. Standard measures were placed before the respondent to quantify the portion size of each food item when administering the questionnaire. The questionnaire was adapted from a questionnaire developed for the urban population residing in South India ${ }^{(19)}$ and has a food list of 127 items, derived from a food database developed from studies at St John's Medical College. Nutrient scores were computed by multiplying the relative frequency of consumption of each food item by the nutrient content of the standard portion size. Nutrient information was obtained on twenty-seven macro- and micronutrients. Energy-adjusted nutrient intakes were calculated by the residual method ${ }^{(20)}$. Data on the amount of food groups consumed were calculated as the total grams of the food groups consumed daily.

\section{Statistical analysis}

Continuous data were summarised as means and standard deviations, and categorical data as numbers and percentages. 
Women who had missing data on any variable were not considered for the analysis involving that variable. The association of anaemia with maternal sociodemographic characteristics and energy-adjusted nutrient intakes, categorized by tertiles, was examined using the $\chi^{2}$ test. The parameters that were found significant in this analysis were considered in multivariable log-binomial regression analysis to examine the independent effect of certain dietary nutrient intakes and food group intakes while adjusting for possible confounding effects of maternal sociodemographic characteristics. All maternal sociodemographic characteristics with $P<0 \cdot 20$ in the univariate analyses were considered in the multivariable model. Characteristics contributing a $>5 \%$ change in the adjusted estimate after exclusion of the covariate from the full model were retained as confounders in the final model. Separate models were constructed for Ca and $\mathrm{P}$ as they were collinear and could not be considered in the same model. Similar analyses were performed with tertiles of intakes of certain food groups which were likely to be associated with anaemia. In addition, Fe intake was retained in the model as an exposure of interest. The presence of effect modification by maternal sociodemographic characteristics, dietary intake of nutrients and food groups was examined using stratified analyses. No effect modification was observed (data not shown). Relative risks (RR) with 95\% confidence intervals and corresponding $P$ values for both unadjusted and adjusted models are presented. Statistical analyses were carried out with the SPSS statistical software package version 16 (SPSS Inc., Chicago, IL, USA). Log-binomial regression analysis was carried out using the PROC GENMOD program in the SAS statistical software package version $9 \cdot 2$ (SAS Institute, Cary, NC, USA).

\section{Results}

The mean age of the pregnant women was $22 \cdot 6$ (SD 3.4) years and the mean gestational age was $11 \cdot 2$ (SD 2.4) weeks (Table 1). High-school graduation was attained by at least $95 \cdot 8 \%$ of the women. A majority of them $(83 \cdot 8 \%)$ were unemployed. Primiparous pregnant women made up $64.5 \%$ of the cohort. The mean weight and height of the women were $47 \cdot 8(\mathrm{sD} 8 \cdot 1) \mathrm{kg}$ and $153 \cdot 0(\mathrm{sD} 5 \cdot 6) \mathrm{cm}$, respectively. BMI was less than $18.5 \mathrm{~kg} / \mathrm{m}^{2}$ in $31.3 \%$ of the women ${ }^{(21)}$. The mean mid-upper arm circumference (an estimate of peripheral muscle and fat mass) and triceps skinfold (an estimate of peripheral fat mass) of the women were $23.6(\mathrm{sD} \mathrm{3 \cdot 1)} \mathrm{cm}$ and 15.6 (SD 5.7) mm, respectively. None of the women were consuming Fe or folate supplements on study entry.

The mean $\mathrm{Hb}$ and haematocrit levels on study entry were $11.5(\mathrm{SD} 1.5) \mathrm{g} / \mathrm{dl}$ and $34.6(\mathrm{SD} 5 \cdot 1) \%$, respectively (Table 2). The prevalence of anaemia $(\mathrm{Hb}<11.0 \mathrm{~g} / \mathrm{dl})$ at baseline was $30 \cdot 3 \%(111 / 366)$. Very few women $(0 \cdot 8 \%)$
Table 1 Baseline sociodemographic and anthropometric characteristics of the study population: pregnant Indian women aged $\geq 18$ and $\leq 40$ years $(n 366)$, enrolled in early pregnancy ( $\leq 14$ weeks of gestation), urban Bangalore, December 2008 to November 2010

\begin{tabular}{|c|c|c|}
\hline Parameter & $n$ & $\%$ \\
\hline \multicolumn{3}{|l|}{ Age (years) (n 366) } \\
\hline$<20$ & 102 & $27 \cdot 9$ \\
\hline $20-24$ & 170 & $46 \cdot 4$ \\
\hline $25-29$ & 77 & $21 \cdot 0$ \\
\hline$\geq 30$ & 17 & $4 \cdot 6$ \\
\hline \multicolumn{3}{|l|}{ Level of education ( $n$ 364) } \\
\hline No formal education & 15 & $4 \cdot 1$ \\
\hline Finished high school (10th grade) & 257 & $70 \cdot 5$ \\
\hline Post high school & 71 & $19 \cdot 5$ \\
\hline University degree and above & 21 & $5 \cdot 8$ \\
\hline \multicolumn{3}{|l|}{ Occupation ( $n$ 364) } \\
\hline Unemployed & 305 & $83 \cdot 8$ \\
\hline Unskilled worker & 21 & $5 \cdot 8$ \\
\hline Skilled worker & 27 & $7 \cdot 4$ \\
\hline $\begin{array}{l}\text { Others (secretarial jobs, teachers, } \\
\text { business, shop owners) }\end{array}$ & 11 & $3 \cdot 1$ \\
\hline \multicolumn{3}{|l|}{ Parity $(n 366)$} \\
\hline 0 & 236 & $64 \cdot 5$ \\
\hline$\geq 1$ & 130 & $35 \cdot 6$ \\
\hline \multirow[t]{2}{*}{$\mathrm{BMI}<18.5 \mathrm{~kg} / \mathrm{m}^{2}(n 364)$} & 114 & $31 \cdot 3$ \\
\hline & Mean & SD \\
\hline Age (years) $(n 366)$ & $22 \cdot 6$ & $3 \cdot 4$ \\
\hline $\begin{array}{l}\text { Gestational age at recruitment by } \\
\text { LMP (weeks) ( } n \text { 366) }\end{array}$ & $11 \cdot 2$ & $2 \cdot 4$ \\
\hline \multicolumn{3}{|l|}{ Anthropometry ( $n$ 364) } \\
\hline Weight $(\mathrm{kg})$ & $47 \cdot 8$ & $8 \cdot 1$ \\
\hline Height $(\mathrm{cm})$ & $153 \cdot 0$ & $5 \cdot 6$ \\
\hline $\mathrm{BMI}\left(\mathrm{kg} / \mathrm{m}^{2}\right)$ & $20 \cdot 4$ & $3 \cdot 3$ \\
\hline Mid-upper arm circumference (cm) & $23 \cdot 6$ & $3 \cdot 1$ \\
\hline \multirow[t]{2}{*}{ Triceps skinfold $(\mathrm{mm})$} & $15 \cdot 6$ & $5 \cdot 7$ \\
\hline & Median & $\begin{array}{l}\text { 25th, } 75 \text { th } \\
\text { percentile }\end{array}$ \\
\hline $\begin{array}{l}\text { Total monthly household income } \\
(\mathrm{Rs})^{\star}(n 365)\end{array}$ & 6000 & 4500,9000 \\
\hline
\end{tabular}

LMP, last menstrual period; Rs, rupees.

* \$US $1=$ Rs $50 \cdot 2$ as of 21 January 2012.

Table 2 Haematological characteristics of the study population: pregnant Indian women aged $\geq 18$ and $\leq 40$ years ( $n 366$ ), enrolled in early pregnancy ( $\leq 14$ weeks of gestation), urban Bangalore, December 2008 to November 2010

\begin{tabular}{lcc}
\hline Parameter & Mean & SD \\
\hline $\mathrm{Hb}(\mathrm{g} / \mathrm{dl})$ & $11 \cdot 5$ & $1 \cdot 5$ \\
Haematocrit $(\%)$ & $34 \cdot 6$ & $5 \cdot 1$ \\
$\mathrm{MCV}(\mathrm{fl})$ & $81 \cdot 1$ & $8 \cdot 9$ \\
$\mathrm{RDW}(\%)$ & $13 \cdot 3$ & $2 \cdot 2$ \\
& $n$ & $\%$ \\
\cline { 2 - 2 } Anaemia $(\mathrm{Hb}<11 \cdot 0 \mathrm{~g} / \mathrm{dl})$ & 111 & $30 \cdot 3$ \\
$\mathrm{Hb}<8.5 \mathrm{~g} / \mathrm{dl}$ & 18 & $4 \cdot 9$ \\
$\mathrm{MCV}<80 \mathrm{fl}$ & 117 & $32 \cdot 0$ \\
$\mathrm{MCV}>90 \mathrm{fl}$ & 37 & $10 \cdot 1$ \\
$\mathrm{RDW}>14 \cdot 5 \%$ & 81 & $22 \cdot 1$ \\
Anaemia and $\mathrm{MCV}<80 \mathrm{fl}$ & 74 & $20 \cdot 2$ \\
Anaemia and $\mathrm{MCV}>90 \mathrm{fl}$ & 2 & $0 \cdot 5$ \\
\hline
\end{tabular}

MCV, mean corpuscular volume; RDW, red-cell distribution width.

had severe anaemia $(\mathrm{Hb}<7 \cdot 0 \mathrm{~g} / \mathrm{dl})$. Nearly one-third of the women had microcytosis $(\mathrm{MCV}<80 \mathrm{fl})$ and $20 \cdot 2 \%$ 


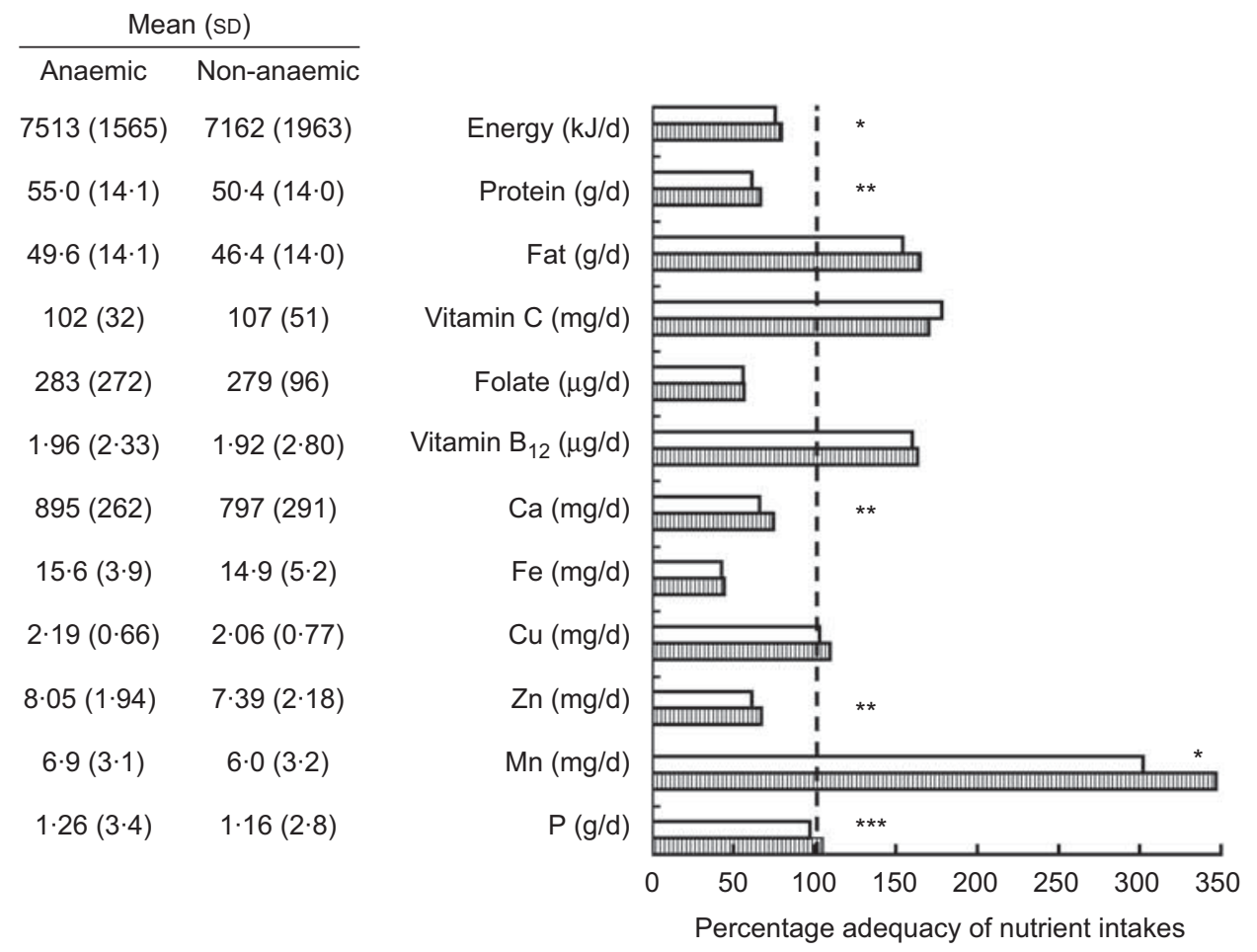

Fig. 1 Dietary intakes, means with standard deviations (left) and as percentage adequacy of the corresponding Indian RDA (right), among anaemic ( $\mathbf{m}, n 110)$ and non-anaemic $(\square, n 252)$ pregnant Indian women aged $\geq 18$ and $\leq 40$ years, enrolled in early pregnancy ( $\leq 14$ weeks of gestation), urban Bangalore, December 2008 to November 2010. Mean values were significantly different between anaemic and non-anaemic pregnant women using the independent $t$ test (two-sided): ${ }^{\star} P<0 \cdot 05,{ }^{\star \star} P<0 \cdot 01$, ${ }^{* * *} P<0.001$

had anaemia with microcytosis. The percentage of women with a red-cell distribution width $>14 \cdot 5 \%$, suggestive of Fe-deficiency anaemia, was $22 \cdot 1 \%$.

The dietary intakes of the anaemic and non-anaemic pregnant women, as means with standard deviations and as percentage adequacy compared with the Indian RDA, are presented in Fig. 1. The mean Fe intakes of anaemic $(15.6 \mathrm{mg} / \mathrm{d})$ and non-anaemic women $(14.9 \mathrm{mg} / \mathrm{d})$ were not significantly different from each other; however, intakes were very low and met only $44.5 \%$ and $42.6 \%$ of the RDA, respectively, in the two groups. Although the overall mean energy intake was low among both anaemic $(7513 \mathrm{~kJ} / \mathrm{d})$ and non-anaemic women $(7162 \mathrm{~kJ} / \mathrm{d})$, it was significantly higher among pregnant women with anaemia compared with those without anaemia $(P<0 \cdot 05)$. Protein intake met between only $60 \%$ and $70 \%$ of the RDA, although it was significantly higher among anaemic pregnant women $(P<0 \cdot 01)$. The percentage adequacy of fat intake was greater than $100 \%$ in comparison to the RDA among both anaemic and non-anaemic pregnant women. Mean dietary intake of Ca was $895 \mathrm{mg} / \mathrm{d}$ among anaemic pregnant women compared with $797 \mathrm{mg} / \mathrm{d}$ among pregnant women without anaemia $(P<0 \cdot 01)$. The dietary intakes of other nutrients known to have an inhibitory effect on Fe absorption, such as $\mathrm{P}, \mathrm{Mn}$ and $\mathrm{Zn}$, were significantly higher among the anaemic pregnant women than those without anaemia $(P<0.001, P=0.03$ and $P=0 \cdot 002$, respectively). The primary food groups contributing towards higher intake of $\mathrm{P}$ in anaemic pregnant women were cereals, pulses and milk and milk products; mean $\mathrm{P}$ intakes from these were $0 \cdot 41$ ( $\mathrm{SD} 0 \cdot 13$ ) $\mathrm{g} / \mathrm{d}, 0 \cdot 11(\mathrm{sD} 0 \cdot 07) \mathrm{g} / \mathrm{d}$ and $0 \cdot 25(\mathrm{sD} 0 \cdot 23) \mathrm{g} / \mathrm{d}$, respectively. The main contributors towards high $\mathrm{Mn}$ intake in anaemic pregnant women were cereals and tea, mean Mn intakes from these being $2 \cdot 6(\mathrm{sD} 0 \cdot 8) \mathrm{mg} / \mathrm{d}$ and $4 \cdot 2$ (sD $2 \cdot 3) \mathrm{mg} / \mathrm{d}$, respectively. The significant difference in intakes of protein, $\mathrm{Ca}, \mathrm{P}, \mathrm{Mn}$ and $\mathrm{Zn}$ between anaemic and non-anaemic pregnant women persisted even after energy adjustment of nutrients. The intakes of vitamin $\mathrm{C}$, vitamin $\mathrm{B}_{12}$ and $\mathrm{Cu}$ were all greater than the RDA and were not significantly different between the two groups. The primary food groups contributing towards higher intake of vitamin $\mathrm{C}$ were vegetables and fruits, with mean vitamin $\mathrm{C}$ intakes of 40.4 (SD 22.5) and $23 \cdot 0$ (sD 26.7) $\mathrm{mg} / \mathrm{d}$, respectively. The main contributor to $\mathrm{Cu}$ intake was cereals (mean $0 \cdot 84$ (SD 0.33) $\mathrm{mg} / \mathrm{d}$ ); while milk and meat contributed towards vitamin $\mathrm{B}_{12}$ intake, mean intakes from the latter being $0.40(\mathrm{SD} 0 \cdot 40)$ and 0.36 (sD $0 \cdot 38) \mu \mathrm{g} / \mathrm{d}$, respectively.

Results of log-binomial regression analyses of anaemia are presented in Table 3. Two separate multivariable models are presented: Model 1 (sociodemographic factors and energy-adjusted micronutrient intakes) and Model 2 (sociodemographic factors and food dietary intakes from 
Table 3 Sociodemographic and nutritional correlates of anaemia among the study population: pregnant Indian women aged $\geq 18$ and $\leq 40$ years ( $n 366$ ), enrolled in early pregnancy ( $\leq 14$ weeks of gestation), urban Bangalore, December 2008 to November 2010

\begin{tabular}{|c|c|c|c|c|c|c|c|c|c|c|}
\hline \multirow[b]{2}{*}{ Parameter } & \multirow[b]{2}{*}{$n / N$} & \multicolumn{3}{|c|}{ Univariate analyses } & \multicolumn{3}{|c|}{ Multivariable Model $1^{\star}(n$ 358) } & \multicolumn{3}{|c|}{ Multivariable Model 2† ( $n$ 358) } \\
\hline & & $\mathrm{RR}$ & $95 \% \mathrm{Cl}$ & $P$ value & Adjusted RR & $95 \% \mathrm{Cl} \ddagger$ & $P$ value & Adjusted RR & $95 \% \mathrm{Cl} \ddagger$ & $P$ value \\
\hline \multicolumn{11}{|l|}{ Occupation } \\
\hline Working at home & $86 / 305$ & $1 \cdot 00$ & Ref. & \multirow[t]{2}{*}{0.016} & $1 \cdot 00$ & Ref. & \multirow[t]{2}{*}{0.06} & $1 \cdot 00$ & Ref. & \multirow[t]{2}{*}{0.05} \\
\hline Working outside the home & $25 / 58$ & 1.53 & $1 \cdot 09,2 \cdot 16$ & & $1 \cdot 45$ & $1 \cdot 01,2 \cdot 09$ & & $1 \cdot 40$ & $1 \cdot 01,1.94$ & \\
\hline \multicolumn{11}{|l|}{ Monthly family income } \\
\hline Tertile $1(<$ Rs 5000) & $43 / 155$ & 1.00 & Ref. & \multirow[t]{3}{*}{$0 \cdot 15$} & 1.00 & Ref. & \multirow[t]{3}{*}{$0 \cdot 14$} & $1 \cdot 00$ & Ref. & \multirow[t]{3}{*}{$0 \cdot 220$} \\
\hline Tertile 2 (Rs 5000-8000) & $26 / 98$ & 0.74 & $0.52,1.05$ & & 0.71 & $0.50,1.02$ & & $0 \cdot 76$ & $0.55,1.05$ & \\
\hline Tertile 3 (>Rs 8000) & $42 / 112$ & $0 \cdot 71$ & $0.47,1.06$ & & 0.73 & $0.49,1.08$ & & $0 \cdot 79$ & $0.53,1 \cdot 17$ & \\
\hline \multicolumn{11}{|l|}{ Education } \\
\hline Less than high school & $37 / 95$ & $1 \cdot 43$ & $0 \cdot 94,2 \cdot 18$ & \multirow[t]{3}{*}{$0 \cdot 12$} & $1 \cdot 36$ & $0 \cdot 89,2 \cdot 09$ & \multirow[t]{3}{*}{$0 \cdot 24$} & $1 \cdot 49$ & $0.98,2.26$ & \multirow[t]{3}{*}{$0 \cdot 11$} \\
\hline High school & $49 / 177$ & 1.02 & $0.67,1.54$ & & 1.04 & $0.68,1.57$ & & $1 \cdot 10$ & $0.73,1 \cdot 64$ & \\
\hline More than high school & $25 / 92$ & $1 \cdot 00$ & Ref. & & $1 \cdot 00$ & Ref. & & $1 \cdot 00$ & Ref. & \\
\hline \multicolumn{11}{|l|}{ Fe intake $(\mathrm{mg} / \mathrm{d})$} \\
\hline Tertile $1(<13 \cdot 9)$ & $32 / 120$ & 0.83 & $0.56,1 \cdot 23$ & \multirow[t]{3}{*}{0.55} & $0 \cdot 76$ & $0.51,1 \cdot 14$ & \multirow[t]{3}{*}{$0 \cdot 41$} & - & & \multirow[t]{3}{*}{-} \\
\hline Tertile $2(13 \cdot 9-15 \cdot 6)$ & $39 / 121$ & 1.00 & $0 \cdot 69,1.44$ & & $0 \cdot 89$ & $0 \cdot 62,1 \cdot 28$ & & - & & \\
\hline Tertile $3(>15 \cdot 6)$ & $39 / 121$ & $1 \cdot 00$ & Ref. & & $1 \cdot 00$ & Ref. & & - & & \\
\hline \multicolumn{11}{|l|}{ Folate intake $(\mu \mathrm{g} / \mathrm{d})$} \\
\hline Tertile $1(<260 \cdot 6)$ & $42 / 120$ & $1 \cdot 46$ & $0 \cdot 98,2 \cdot 18$ & \multirow[t]{3}{*}{$0 \cdot 15$} & $1 \cdot 36$ & $0 \cdot 89,2 \cdot 07$ & \multirow[t]{3}{*}{$0 \cdot 34$} & - & & \multirow[t]{3}{*}{-} \\
\hline Tertile $2(260 \cdot 6-293 \cdot 5)$ & $39 / 121$ & $1 \cdot 34$ & $0.89,2 \cdot 02$ & & 1.25 & $0.83,1.89$ & & - & & \\
\hline Tertile $3(>293.5)$ & $29 / 121$ & $1 \cdot 00$ & Ref. & & $1 \cdot 00$ & Ref. & & _- & & \\
\hline Ca intake $(\mathrm{mg} / \mathrm{d})$ & & & & & & & & & & \\
\hline Tertile $1(<738 \cdot 7)$ & $24 / 121$ & $1 \cdot 00$ & Ref. & 0.006 & $1 \cdot 00$ & Ref. & 0.02 & - & & - \\
\hline Tertile $2(738 \cdot 7-887 \cdot 7)$ & $41 / 121$ & $1 \cdot 71$ & $1 \cdot 10,2 \cdot 64$ & & 1.59 & $1 \cdot 04,2 \cdot 42$ & & - & & \\
\hline Tertile $3(>887 \cdot 7)$ & $45 / 120$ & $1 \cdot 89$ & $1 \cdot 23,2 \cdot 90$ & & $1 \cdot 79$ & $1 \cdot 16,2 \cdot 76$ & & - & & \\
\hline$P$ intake $(\mathrm{mg} / \mathrm{d}) \S$ & & & & & & & & & & \\
\hline Tertile $1(<1147 \cdot 1)$ & $25 / 121$ & 1.00 & Ref. & $<0.001$ & 1.00 & Ref. & 0.002 & - & & - \\
\hline Tertile $2(1147 \cdot 1-1234 \cdot 3)$ & $34 / 121$ & $1 \cdot 36$ & $0 \cdot 87,2 \cdot 13$ & & $1 \cdot 28$ & $0 \cdot 82,1 \cdot 98$ & & - & & \\
\hline Tertile $3(>1243 \cdot 3)$ & $51 / 120$ & $2 \cdot 06$ & $1.37,3.09$ & & 1.96 & $1 \cdot 30,2 \cdot 96$ & & - & & \\
\hline Fibre intake $(\mathrm{g} / \mathrm{d})$ & & & & & & & & & & \\
\hline Tertile $1(<4 \cdot 1)$ & $30 / 121$ & 1.00 & Ref. & $0 \cdot 15$ & - & & - & 1.00 & Ref. & $0 \cdot 11$ \\
\hline Tertile $2(4 \cdot 1-6 \cdot 2)$ & $36 / 120$ & $1 \cdot 21$ & $0 \cdot 80,1 \cdot 83$ & & - & & - & $1 \cdot 18$ & $0 \cdot 80,1 \cdot 74$ & \\
\hline Tertile $3(>6 \cdot 2)$ & $44 / 121$ & $1 \cdot 47$ & $0 \cdot 99,2 \cdot 17$ & & - & & - & $1 \cdot 46$ & $1 \cdot 01,2 \cdot 11$ & \\
\hline Meat, poultry \& fish intake ( $\mathrm{g}$ & & & & & & & & & & \\
\hline Tertile $1(<9 \cdot 2)$ & $24 / 121$ & 1.00 & Ref. & 0.002 & - & & - & $1 \cdot 00$ & Ref. & 0.002 \\
\hline Tertile $2(9 \cdot 2-25 \cdot 6)$ & $37 / 123$ & 1.52 & $0 \cdot 97,2 \cdot 37$ & & - & & - & $1 \cdot 35$ & $0 \cdot 87,2 \cdot 10$ & \\
\hline Tertile $3(>25 \cdot 6)$ & $49 / 118$ & $2 \cdot 09$ & $1 \cdot 38,3 \cdot 18$ & & - & & - & 1.94 & $1 \cdot 29,2 \cdot 91$ & \\
\hline
\end{tabular}

RR, relative risk; Ref. referent category.

$P$ values (two-sided) are reported for the adjusted RR

${ }^{*}$ Multivariable log-binomial regression of anaemia $v$. occupation, monthly family income, education, $\mathrm{Fe}, \mathrm{Ca}$, folate and $\mathrm{P}$ intakes.

tMultivariable log-binomial regression of anaemia $v$. occupation, monthly family income, education, fibre and meat, poultry \& fish intakes.

$\S$ Due to collinearity of $\mathrm{Ca}$ and $\mathrm{P}$ intakes $(r=0 \cdot 8)$, the adjusted RR for dietary $\mathrm{P}$ intakes were obtained from a separate model adjusted for the effects of the other variables in the model. 
food groups). In the univariate analyses, the sociodemographic variable that was significantly associated with a higher prevalence of anaemia was working outside the home $(P=0 \cdot 016)$. Maternal age, parity, income and education were not associated with anaemia. Energyadjusted nutrient intakes associated with higher prevalence of anaemia included higher intake of $\mathrm{Ca}$ and $\mathrm{P}(P=0.006$ and $P<0 \cdot 001$, respectively). In multivariable Model 1 , working outside the home was no longer associated with anaemia. The significant association of $\mathrm{Ca}$ and $\mathrm{P}$ intakes with anaemia observed in the univariate analyses persisted in the multivariable Model 1 (Table 3).

In multivariable Model 2 (Table 3 ), the RR of anaemia was higher for pregnant women with the greatest intakes of meat, fish and poultry ( $\mathrm{RR}=1 \cdot 94 ; 95 \% \mathrm{CI} 1 \cdot 29,2 \cdot 91)$, consistent with the univariate analyses. The relationship of milk intake with anaemia did not show a monotonic trend and was not significant in either the univariate or multivariable analyses.

\section{Discussion}

In a cross-sectional analysis of 366 urban pregnant Indian women, we found a high prevalence of both anaemia $(30 \cdot 3 \%)$ and microcytic anaemia $(20 \cdot 2 \%)$ during the first trimester of pregnancy. Among these pregnant women, who had low intakes of $\mathrm{Fe}$ and several other nutrients, higher intakes of $\mathrm{Ca}$ and $\mathrm{P}$ (dietary components known to inhibit $\mathrm{Fe}$ absorption) were independently associated with a higher prevalence of anaemia.

Our study is unique in that we have identified the prevalence and dietary correlates of anaemia as early as $\leq 14$ weeks of gestation. A study from the urban areas of Udipi, Karnataka found the prevalence of anaemia to be $50 \cdot 1 \%$ ( $\mathrm{Hb}$ determined by the cyanmethaemoglobin method) among pregnant women at $\leq 14$ weeks of gestation, and identified age, parity, education, socio-economic status, compliance with Fe supplements, history of bleeding and food selection ability as significant determinants of anaemia; however, dietary factors were not studied ${ }^{(22)}$. Other studies have reported a higher prevalence of anaemia than our reported rate of $30.3 \%$ but these have been carried out among pregnant women later in pregnancy and have used different methods of measuring $\mathrm{Hb}^{(23-25)}$. The present anaemia prevalence is also lower than the published figures of $59 \%$ for any anaemia among pregnant Indian women ${ }^{(5)}$ and $32 \%$ for moderate to severe anaemia among pregnant women in Karnataka(7). This may be attributed to the fact that our study was a hospital-based study recruiting urban women in early pregnancy based on strict inclusion and exclusion criteria, and possible differences in the method of $\mathrm{Hb}$ analysis. It is also noteworthy that the years of schooling attained by pregnant women in our cohort were generally higher in comparison to the overall level of education attainment by pregnant women from urban Karnataka ${ }^{(26)}$.
Nevertheless, a prevalence of $30 \cdot 3 \%$ anaemia is in itself an indication that anaemia continues to be a problem of public health significance among pregnant Indian women.

Our results indicate that nearly one-third of the pregnant women had BMI $<18 \cdot 5 \mathrm{~kg} / \mathrm{m}^{2}$. This is in accordance with nationally representative data from the National Family Health Survey that has shown more than one-third of women to have a BMI $<18 \cdot 5 \mathrm{~kg} / \mathrm{m}^{2}$, reflecting chronic energy and micronutrient deficiencies ${ }^{(27)}$. The mean intakes of several macro- and micronutrients were well below the RDA for both pregnant anaemic and non-anaemic women. For example, the energy intake was low in comparison to the RDA among all pregnant women in our cohort, although it was higher among the anaemic pregnant women compared with the nonanaemic pregnant women possibly reflecting a diet high in energy but poor in quality. Similar low intake of energy has been reported among pregnant women from urban South India during early pregnancy ${ }^{(28)}$. The mean dietary intake of $\mathrm{Fe}$ was less than $50 \%$ of the RDA. It is noteworthy that all of the pregnant women were $\leq 14$ weeks of gestational age and at enrolment none was receiving Fe or folic acid supplements. Perhaps because of the low and narrow range of dietary Fe intake, we did not observe any association of Fe intake with anaemia. These results are consistent with data from the National Nutrition Monitoring Bureau surveys in India that also showed no correlation of Fe intake with anaemia ${ }^{(13)}$. Vitamin C is known to have an enhancing and dose-dependent effect on Fe absorption in many single-meal radioisotope studies in human volunteers ${ }^{(29)}$, and can overcome the negative effect of inhibitors on Fe absorption ${ }^{(30)}$. However prolonged cooking and storage of food can reduce its enhancing effect ${ }^{(31)}$. Although the mean intake of vitamin $\mathrm{C}$ among pregnant women in our cohort exceeded the RDA, it was apparently not sufficient to overcome the inhibitory effect of Fe absorption inhibitors such as $\mathrm{P}$ and $\mathrm{Ca}$. This may be due to practices commonly observed among these women, such as prolonged cooking and allowing the meals to stand for longer durations. On the contrary, intakes of $\mathrm{Fe}$ absorption inhibitors such as $\mathrm{Mn}, \mathrm{P}$ and $\mathrm{Zn}$ were higher in anaemic pregnant women.

In the setting of low dietary Fe intake, the intakes of several other nutrients and their role in increasing the risk of anaemia through possible interactions with Fe are important to consider. A higher intake of Mn may impose a risk for reduced Fe utilization by affecting Fe absorption, while higher doses of $\mathrm{Zn}$ in aqueous solutions are known to impair Fe absorption, although this effect has not been observed when $\mathrm{Zn}$ was added to meals ${ }^{(32)}$. Among pregnant women we observed that higher intake of $\mathrm{Ca}$ was associated with a greater risk of anaemia. In single-meal studies conducted in adult men and women, $\mathrm{CaCl}_{2}$ at doses ranging from 40 to $300 \mathrm{mg}$ had a dosedependent inhibitory effect on the absorption of $5 \mathrm{mg}$ 
non-haem Fe, and $165 \mathrm{mg}$ of $\mathrm{Ca}$ given as milk, cheese or $\mathrm{CaCl}_{2}$ diminished absorption of $5 \mathrm{mg}$ haem $\mathrm{Fe}^{(33,34)}$. More recently, an isolated effect of $\mathrm{CaCl}_{2}$ on absorption of both $5 \mathrm{mg}$ non-haem $\mathrm{Fe}$ and haem Fe was observed at Ca doses $\geq 1000 \mathrm{mg}$ and $800 \mathrm{mg}$, respectively, among non-pregnant women ${ }^{(35)}$. The effect of Ca supplementation on the uptake of haem $\mathrm{Fe}$ is independent of $\mathrm{Fe}$ bioavailability in the meal ${ }^{(36)}$ and is a direct effect on haem Fe absorption rather than an indirect counteracting effect on the enhancing effect of meat ${ }^{(37)}$. This effect is not only seen when $\mathrm{Ca}$ and $\mathrm{Fe}$ are taken together in the same meal ${ }^{(38,39)}$. Ca is known to inhibit Fe absorption by the formation of poorly soluble calcium phytate complexes $^{(40)}$ or at the cellular level by its effect on DMT 1 (divalent metal-ion transporter-1) receptors ${ }^{(41)}$. The competitive inhibition between $\mathrm{Ca}$ and $\mathrm{Fe}$ in the final transport steps from the mucosal cells to the plasma, common for haem and non-haem $\mathrm{Fe}$, has also been suggested $^{(33)}$. This significant association of dietary Ca intake with anaemia may have a greater relevance among pregnant women from India because of their inadequate Fe stores, overall low intakes of both $\mathrm{Fe}$ and $\mathrm{Ca}$, a predominantly cereal/pulse-based diet and the relative low Fe bioavailability of Indian meals.

Higher intake of $\mathrm{P}$ was also observed to be an independent risk factor for anaemia among pregnant women in the present study. $\mathrm{P}$ may have a direct inhibitory effect on Fe absorption ${ }^{(42)}$. Even relatively small quantities of residual phytate, which is the storage form of $\mathrm{P}(<10 \mathrm{mg}$ phytic acid/meal), are known to strongly inhibit Fe absorption ${ }^{(43)}$. Although we did not analyse the phytate content in the meals of women in this current cohort, results from another study in a similar group of young women of low socioeconomic status from Bangalore showed that the phytate content in their diets was as high as $1287 \mathrm{mg} / \mathrm{d}^{(44)}$. We also observed that a higher intake of meat was associated with a greater risk of anaemia. It is, however, noteworthy that the median (25th, 75th percentile) intake of meat even in the highest group of meat intake was only $39(32,50) \mathrm{g} / \mathrm{d}$, making it difficult to draw any conclusions about the relationship between meat intake and anaemia.

In addition to the nutritional factors that cause anaemia, chronic Fe losses due to parasitic infections such as hookworm and schistosomiasis may cause anaemia ${ }^{(44)}$. We did not evaluate for the presence of parasitic infections among pregnant women in our cohort; however, a low prevalence of parasitic infections has been previously reported among women from urban slums in South India ${ }^{(44)}$. Our study is limited in that the dietary data were recorded with an FFQ and not via alternative methods including prospective food weighing and other techniques. However, we did employ a validated FFQ with a trained interviewer and portion sizes to minimize recall bias. Fluctuations in appetite and nausea commonly experienced by pregnant women in the first trimester may have influenced reported dietary intakes ${ }^{(45)}$. Further, our assessment of Fe status was limited to red-blood-cell morphologic indices. The results of our study are based on cross-sectional data with a moderate sample size, so caution should be exercised when drawing conclusions, especially for different populations. In addition, our study results are based on a sample of pregnant women enrolled in a clinical trial at a single hospital and therefore the findings may not be representative of all urban Indian pregnant women.

\section{Conclusions}

The results of the present study indicate that higher intakes of $\mathrm{Ca}$ and $\mathrm{P}$ may be important correlates of anaemia among women with low Fe intake. Further research is warranted to elucidate the modulatory effect of $\mathrm{Ca}$ and $\mathrm{P}$ on $\mathrm{Fe}$ absorption and the levels at which these effects are pronounced among pregnant women in the Indian subcontinent, where such effects have not been previously documented.

\section{Acknowledgements}

This research was financially supported by the Indian Council of Medical Research, India (ICMR: 5/7/192/06RHN) and the National Institutes of Health, USA (NICHD HD052143 and NICHD K24 HD058795). None of the authors has any personal or financial conflict of interest. T.M.S. was involved in data collection and wrote the first draft of the manuscript; T.T. was involved in analysis and writing of the manuscript; J.F. was involved in data analysis; R.B. was involved in data analysis and manuscript writing; R.R. was involved in data collection; S.M.V. was involved in manuscript writing; K.S. was involved in conception of the study design, supervision of data collection and manuscript writing; A.V.K. was involved in conception of the study design and writing of the manuscript; C.D. was involved in conception of the study design, supervision of data collection, data analysis and manuscript writing. The data were presented in part at Experimental Biology 2011 (Washington, DC, 9-13 April 2011). The authors thank the pregnant women for their participation in the study. They are grateful to Dr B Nirmala in obtaining all clearances to conduct the study at Hosahalli Referral Hospital and thank the doctors, nurses and technical staff at the hospital for their support. The authors also acknowledge Dr S Muthayya for her assistance during the study; and thank Ms Vijaya, Ms Surekha, Ms Devi, Ms Asha, Ms Shilpa, Ms Ammu, Ms Asha, Ms Preethi and Ms Poornima for technical support.

\section{References}

1. World Health Organization/Centers for Disease Control and Prevention (2004) Assessing the Iron Status of Populations. Joint Report by World Health Organization/ 
Centers for Disease Control and Prevention Technical Consultation on the Assessment of Iron Status at the Population Level, Geneva, Switzerland. Geneva: WHO.

2. Allen LH (1997) Pregnancy and iron deficiency: unresolved issues. Nutr Rev 55, 91-101.

3. Scholl TO \& Hediger ML (1994) Anemia and iron deficiency anemia: compilation of data on pregnancy outcome. Am J Clin Nutr 59, 2 Suppl., 492S-500S.

4. Scanlon KS, Yip R, Schieve LA et al. (2000) High and low hemoglobin during pregnancy: differential risks for preterm and small for gestational age. Obstet Gynecol 96 , 741-748.

5. International Institute of Population Sciences \& ORC Macro (2007) National Family Health Survey (NHFS-3), 2005-06: India. Mumbai: IIPS

6. Toteja GS, Singh P, Dhillon BS et al. (2006) Prevalence of anemia among pregnant women and adolescent girls in 16 districts of India. Food Nutr Bull 27, 311-315.

7. International Institute of Population Sciences \& Ministry of Health and Family Welfare, Government of India (2006) Nutritional status of children and prevalence of anemia among children, adolescent girls and pregnant women. District Level Household Survey on Reproductive and Child Health, India, 2002-2004. http://www.rchiips.org/pdf/ rch2/National_Nutrition_Report_RCH-II.pdf (accessed May 2011)

8. Yajnik CS, Deshpande SS, Jackson AA et al. (2008) Vitamin B12 and folate concentrations during pregnancy and insulin resistance in the offspring: the Pune Maternal Nutrition Study. Diabetologia 51, 29-38.

9. National Nutrition Monitoring Bureau (2003) Prevalence of Micronutrient Deficiencies. NNMB Technical Report no. 22. Hyderabad: National Institute of Nutrition, Indian Council of Medical Research.

10. Bamji MS \& Lakshmi AV (1998) Less recognised micronutrient deficiencies in India. NFI Bull 19, 5-8.

11. Vanderjagt DJ, Brock HS, Melah GS et al. (2007) Nutritional factors associated with anemia in pregnant women in Northern Nigeria. J Health Popul Nutr 25, 75-81.

12. Agarwal KN, Agarwal DK \& Sharma A (2005) Anemia in Pregnancy - Interstate Differences. Scientific Report no. 16. New Delhi: Nutrition Foundation of India.

13. Nair MK \& Vasuprada Iyengar (2009) Iron content, bioavailability and factors affecting iron status of Indians. Indian J Med Res 130, 634-645.

14. Ministry of Home Affairs, Government of India (2011) Provisional population tables: India: Census 2011. http:// censusindia.gov.in/2011-prov-results/prov_rep_tables.html (accessed July 2011).

15. Navaneetham K \& Dharmalingam A (2000) Utilization of Maternal Health Care Services in South India. Trivandrum: Centre for Development Studies.

16. Bharati P, Som S, Chakrabarty S et al. (2008) Prevalence of anemia and its determinants among non pregnant and pregnant women in India. Asia Pac J Public Health 20 , 347-359.

17. Rempher KJ \& Little J (2004) Assessment of red blood cell and coagulation laboratory data. AACN Clin Issues 15, 622-637.

18. UNICEF/United Nations University/World Health Organization (2001) Iron Deficiency Anemia. Assessment, Prevention and Control. A Guide for Programme Managers. WHO/NHD/01.3. Geneva: WHO.

19. Bharathi AV, Kurpad AV, Thomas T et al. (2008) Development of food frequency questionnaires and a nutrient database for the Prospective Urban and Rural Epidemiological (PURE) pilot study in South India: methodological issues. Asia Pac J Clin Nutr 17, 178-185.

20. Willett WC (1998) Nutritional Epidemiology, 2nd ed. New York: Oxford University Press.
21. World Health Organization (1995) Physical Status: The Use and Interpretation of Anthropometry. Geneva: WHO.

22. Noronha JA, Bhaduri A, Vinod Bhat H et al. (2010) Maternal risk factors and anemia in pregnancy: a prospective retrospective cohort study. J Obstet Gynaecol 30, 132-136.

23. Seck BC \& Jackson RT (2010) Multiple contributors to iron deficiency and anemia in Senegal. Int J Food Sci Nutr 61, 204-216.

24. Ahmed F, Mahmuda I, Sattar A et al. (2003) Anemia and vitamin A deficiency in poor urban pregnant women of Bangladesh. Asia Pac J Clin Nutr 12, 460-466.

25. Van den Broek NR, Rogerson SJ, Mhango CG et al. (2000) Anemia in pregnancy in Southern Malawi: prevalence and risk factors. BJOG 107, 445-451.

26. International Institute for Population Sciences (2010) District Level Household and Facility Survey (DLHS-3), 2007-08: India. Mumbai: IIPS

27. International Institute for Population Sciences \& ORC Macro (2000) National Family Health Survey India 1998-1999. Mumbai: Andhra Pradesh International Institute for Population Sciences.

28. Piers LS, Diggavi SN, Thangam S et al. (1995) Changes in energy expenditure, anthropometry, and energy intake during the course of pregnancy and lactation in wellnourished Indian women. Am J Clin Nutr 61, 501-513.

29. Lynch SR \& Cook JD (1980) Interaction of vitamin C and iron. Ann N Y Acad Sci 355, 32-44.

30. Hurrell R \& Egli I (2010) Iron bioavailability and dietary reference values. Am J Clin Nutr 91, issue 5, 1461S-1467S.

31. Teucher B, Olivares M \& Cori H (2004) Enhancers of iron absorption: ascorbic acid and other organic acids. Int $J$ Vitam Nutr Res 74, 403-419.

32. Rossander-Hultén L, Brune M, Sandström B et al. (1991) Competitive inhibition of iron absorption by manganese and zinc in humans. Am J Clin Nutr 54, 152-156.

33. Hallberg L, Brune M, Erlandsson M et al. (1991) Calcium: effect of different amounts on nonheme and hemeiron absorption in humans. Am J Clin Nutr 53, 112-119.

34. Hallberg L, Rossander-Hulthén L, Brune M et al. (1993) Inhibition of haem-iron absorption in man by calcium. $\mathrm{BrJ}$ Nutr 69, 533-540.

35. Gaitan D, Flores S, Saavedra P et al. (2011) Calcium does not inhibit the absorption of 5 milligrams of nonheme or heme iron at doses less than 800 milligrams in non pregnant women. J Nutr 141, 1652-1656.

36. Roughead ZK, Zito CA \& Hunt JR (2005) Inhibitory effects of dietary calcium on the initial uptake and subsequent retention of heme and nonheme iron in humans: comparisons using an intestinal lavage method. Am J Clin Nutr 82, 589-597.

37. Hallberg L, Rossander-Hultén L, Brune M et al. (1992) Calcium and iron absorption: mechanism of action and nutritional importance. Eur J Clin Nutr 46, 317-327.

38. Gleerup A, Rossander-Hulthén L, Gramatkovski E et al. (1995) Iron absorption from the whole diet: comparison of the effect of two different distributions of daily calcium intake. Am J Clin Nutr 61, 97-104.

39. Van de Vijver LP, Kardinaal AF, Charzewska J et al. (1999) Calcium intake is weakly but consistently negatively associated with iron status in girls and women in six European countries. J Nutr 129, 963-968.

40. Zhou JR \& Erdman JW (1995) Phytic acid in health and disease. Crit Rev Food Sci Nutr 35, 495-508.

41. Shawki A \& Mackenzie B (2010) Interaction of calcium with human divalent metal-ion transporter-1. Biochem Biophys Res Commun 393, 471-475.

42. Monsen ER \& Cook JD (1976) Food iron absorption in human subjects: the effects of calcium and phosphorus salts on the absorption of nonheme iron. Am J Clin Nutr 29, 1142-1148. 
43. Hurrell RF, Reddy MB, Juillerat MA et al. (2003) Degradation of phytic acid in cereal porridges improves iron absorption by human subjects. Am J Clin Nutr 77, 1213-1219.

44. Thankachan P, Muthayya S, Walczyk T et al. (2007) An analysis of the etiology of anemia and iron deficiency in young women of low socioeconomic status in Bangalore, India. Food Nutr Bull 28, 328-336.

45. Cheng Y, Yan H, Dibley MJ et al. (2008) Validity and reproducibility of a semi-quantitative food frequency questionnaire for use among pregnant women in rural China. Asia Pac J Clin Nutr 17, 166-177. 